\title{
Family Medicine and Community Health \\ Family medicine residency training in Ghana after 20 years: resident attitudes about their education
}

\author{
Ghazwan Toma (D) , ${ }^{1}$ Akye Essuman (D) , ${ }^{2}$ Michael D Fetters (D) ${ }^{1,3}$
}

To cite: Toma G, Essuman A, Fetters MD. Family medicine residency training in Ghana after 20 years: resident attitudes about their education. Fam Med Com Health 2020;8:e000394. doi:10.1136/fmch-2020-000394

Check for updates

(c) Author(s) (or their employer(s)) 2020. Re-use permitted under CC BY-NC. No commercial re-use. See rights and permissions. Published by BMJ.

${ }^{1}$ Department of Family Medicine, University of Michigan, Ann Arbor, Michigan, USA

${ }^{2}$ Family Medicine Unit Department of Community Health, University of Ghana, Accra, Ghana

${ }^{3}$ Mixed Methods Program, University of Michigan, Ann Arbor, Michigan, USA

Correspondence to Dr Ghazwan Toma; gtoma@umich.edu

\section{ABSTRACT}

Objective In addition to assessing educational needs of family medicine trainees in Ghana, we sought to assess whether those entering the training programme aimed to pursue an academic career.

Design A case study using an anonymous cross-sectional survey through collaboration between faculty members from the family medicine departments of Ghana and the University of Michigan.

Setting The family medicine postgraduate trainees and the most recent graduates in the three training sites, Accra, Kumasi and Mampong, as well as modular residents in Ghana served as the targeted participants during data collection between October and November of 2018.

Participants Second and third year family medicine residents, fellows (known as senior residents in Ghana) and recent graduates were invited to participate in this study. Thirty-five of 77 eligible subjects provided responses ( $46 \%$ response rate), but five records were eliminated due to incomplete data to yield a survey completion rate of $39 \%(30 / 77)$.

Result Participants were mostly men $(n=19)$, and the average age of respondents was 37 years old. The participants indicated the residency programmes needed more faculty $97 \%(n=29)$, supervision during outpatient care $87 \%(n=26)$ and lectures $83 \%(n=25)$. The main reason provided by respondents for entering residency programme in family medicine, which is currently not required for practising primary care in Ghana, was to obtain more education $93 \%(n=28)$. Participants who had completed the residency programme were much more likely to be interested in becoming faculty compared with those still in residency $(p<0.001)$.

Conclusion The research confirms the need for more faculty and the importance of investing in faculty development resources for ensuring a robust programme. These findings provide constructive feedback that could improve residency curricula of the local and regional family medicine training programmes and supports investing in trainees and new graduates as future faculty candidates.

\section{INTRODUCTION}

The richness of the family medicine discipline goes beyond its encompassing many aspects of other disciplines, because it is an approach where family physicians consider patients' own values, their beliefs and environments while also collaborating with many

\section{Key points}

\section{Question}

- While the family medicine training programmes in Ghana have achieved remarkable development with limited resources in just two decades, there remains a desperate shortage of practitioners and family medicine faculty. We sought to understand current and recent trainees' attitudes about their training and interest in academic family medicine.

\section{Findings}

- Most respondents felt the programme provided high-quality teaching. Participants who had completed the residency programme were much more likely to be interested in becoming faculty compared with those still in residency $(p<0.001)$. Primary needs identified included more faculty $97 \%(n=29)$, supervision during outpatient care $87 \%(n=26)$ and lectures $83 \%(n=25)$.

\section{Meaning}

- The findings suggest significant success in development of family medicine in Ghana and also indicate the need for more faculty and faculty development activities based on family medicine trainees' perspectives. The findings also suggest investing in trainees and new graduates as future faculty candidates.

specialists. ${ }^{12}$ Leaders in healthcare in Africa are increasingly realising the importance of family physicians, especially for rural areas. ${ }^{3}$ Family physicians are often the first contact for patients regardless of age, gender or religion. Global reports indicate there are disparities in cancer and non-communicable disease prevention, and therefore mortality, between low-income and middle-income countries and high-income countries. ${ }^{4}$ Policy makers seeking an efficient health system need to focus on community health, a task adeptly handled by primary care physicians.

Developing a new residency programme in sub-Saharan Africa is a challenging undertaking, and its success is at least partially reliant on local and regional collaboration. ${ }^{5}$ 
On one hand, main challenges are developing appropriate and culturally customised curriculum as well as ensuring there are resources for its success. ${ }^{6}$ On the other hand, comparisons between Ethiopia and the USA, Japan and the USA and from China, suggest that resident perspectives about fundamental training challenges in family medicine are more similar than dissimilar. ${ }^{7-9}$ The residency programmes' curricula periodically undergoes formal review and changes when the need arises, especially when needs are expressed by the current trainees in the setting of dedicated, supportive and transparent faculty members. Residency programmes ideally should undergo some formal evaluation in order to be sure they are providing adequate teaching and supervision for trainees. ${ }^{10}$ Residents are an important constituency as the training is designed for their development and their perspectives on training merit consideration.

The population in Ghana is ageing rapidly with a concomitant increase in complexity of medical care and chronic illnesses. ${ }^{11}$ Previous research has shown there is limited care access for critical conditions such as stroke and large variability in the quality of care. ${ }^{12}$ Chronic medical conditions such as hypertension, coronary artery disease and diabetes are prevalent, and the population faces access challenges for achieving delivery of highquality care and preventive services. ${ }^{3} 14$ The success of Ghana's health system is dependent on having qualified primary care doctors especially in rural areas. ${ }^{15}$ Family physicians can handle the majority of the health needs of patients in rural districts. Moreover, they are crucial in tertiary centres where they can serve the primary care needs of the large population centres and serve as a gateway for specialists, a feature that contributes to cost effective care for the Ghanaian health system without compromising the quality of care. ${ }^{16}$ Unfortunately, previous data suggest Ghanaians have much worse cardiovascular health compared with the European population. ${ }^{17} 18$ Additionally, research has shown that having a health system that allows access, awareness and education to diabetes and hypertension resources will improve the outcome of these illnesses. ${ }^{19}$ While a system based on family medicine seems an obvious solution, family medicine faces a significant challenges.

In Ghana, medical school graduates can practice primary care once they complete a 2-year internship even without completing formal residency training programme in primary care afterwards. This is important first because there are many medical school graduates who opt to leave the country, despite the establishment of the Ghana College of Physicians and Surgeons and proactive efforts to retain medical school graduates. ${ }^{20}$ Ghana needs to retain its medical school graduates to train and practice. Unfortunately, graduates increasingly have been leaving Ghana to practice in high-income countries, though some opt to enter family medicine training programmes. ${ }^{21}{ }^{22}$ While medical schools are proud of their emigrants' achievements and success abroad, a national health priority is to retain these graduates and provide them with opportunity to progress in their career inside their home country. ${ }^{23}$ In contrast to many highincome countries, medical student graduates in Ghana are licenced to work as clinicians after a 2-year internship as formal residency training is not required to practice. Among speculated reasons for why medical students chose to enter residency programmes is the extra training and supervision that they will obtain to support them when they practice independently. Pursuing such training abroad will potentially confer financial benefits and prestige. Engaging in teaching and scholarly activities could prove to be an appealing factor for enrolling in formal training programmes in the homeland. Given the need to minimise brain drain from Ghana and to retain medical school graduates for training in family medicine, research to better understand motivations of trainees who remain in Ghana for training in family medicine is needed.

While establishing a family medicine residency training programme in Ghana faces many challenges as in many other countries in sub-Saharan Africa, the need is great. ${ }^{524}$ This is especially true in rural district hospitals of West Africa. ${ }^{25}{ }^{26}$ Like many other sub-Saharan African countries, family physicians' responsibilities in Ghana are evolving especially given advances in healthcare, an increasing prevalence of chronic diseases, and an ageing population. ${ }^{27}$ Family physicians' roles differ substantially among physicians practising in the same country depending on whether they practice in urban versus rural areas. ${ }^{28}$ Their potential varies based on where they completed their postgraduate training. ${ }^{29}$ There is a good evidence to support the effectiveness of population health programmes and their role in improving community health in Ghana. ${ }^{30}$ Given the rise of chronic noncommunicable diseases in Ghana, there is even more concern about the need for expansion as the available programmes are already inadequate to handle the need. ${ }^{32}$ These circumstances further emphasise the need for family medicine residency training in Ghana.

The family medicine residency in Ghana started in 1999 and has experienced remarkable development with limited resources. Residents often need a sponsor who will financially support them during residency training. This is a critical issue because sponsored residents need to payback the financial support received by working for the sponsor after completing residency. This limits a resident's ability to pursue an academic career in family medicine despite the dire need for faculty. The Ghana family medicine training programme has two components. The first is a 3-year training programme that can be initiated after completing the 2-year required internship. Residency graduates earn prestigious membership of the Ghana College of Physicians and Surgeons. Regarding the second, they can subsequently apply for an optional 2-year research-based fellowship (such a trainee is called a senior resident in Ghana and is comparable with a fellow in the US model). At the time of this research, there had been nearly 100 family medicine training programme graduates from the three training sites in Accra, Kumasi 
and Mampong. The fund for family medicine training in Ghana is primarily through the Ministry of Health, which receives its funds from the Ghanaian Government.

In Ghana, licenced medical officers may not undergo further formal training after internship. They are generalists who rise through the ranks by informal training and years of service. Medical officers do practice broadspectrum primary care, but they gain different expertise depending on their location of practice and their years of practice. Family physicians with further formal training after internship are designated as specialists (after residency) and senior specialists (after completing senior residency known as fellowship in US systems).

Practice scope, professional recognition and remuneration are therefore different for the two groups although they both work in primary care facilities.

The family medicine department at the University of Michigan, USA began collaborating with their Ghanaian colleagues in 2008 to support and sustain primary care education and research in Ghana. This collaboration has proven a productive one given extensive scholarly activities and publications. ${ }^{33-39}$ The collaboration has involved faculty exchanges between Michigan and Ghana. Faculty from the University of Michigan have provided lectures and supported the certifying examination process in Ghana. Ghanaian faculty have participated in research and faculty development in the University of Michigan. Moreover, the Department of Family Medicine at the University of Michigan helped coordinate a collaboration between the Geriatric Division of the University of Michigan and Department of Family Medicine in Ghana that fostered the establishment of the first training programme in geriatric medicine in Ghana. ${ }^{40}$ These efforts not notwithstanding, there remains a need for adequate faculty development resources in Ghana to support faculty growth and their endeavours teaching and supporting their trainees. ${ }^{41} 42$ The critical need is for more faculty development resources that currently are both limited and challenging to access even when they become available. $^{43}$

It is not well known what is needed for the programme success and sustainability and why medical school graduates would choose additional family medicine training when they can practice primary care after the 2-year internship. Moreover, information is lacking about how Ghanaian family medicine trainees view the teaching they receive and what teaching formats are needed most. Thus, we conducted research to understand current trainees' and recent graduates' views about their education and interest in teaching.

\section{METHODS}

\section{Design}

We conducted a case study design through use of an anonymous cross-sectional survey. The case study was bounded by the three residency programmes of the Ghana family medicine residency. The survey was designed using the
Qualtrics survey platform in a collaboration between faculty from the family medicine departments of the Ghana College of Physicians and Surgeons and the University of Michigan.

\section{Setting}

The family medicine postgraduate trainees in the three training sites, Accra, Kumasi and Mampong, as well as modular residents in Ghana served as the targeted participants during data collection from October and November of 2018. Accra is the capital of Ghana and home to the country's premier health facility, Korle-Bu Teaching Hospital, where the family medicine programme is located. Kumasi is the second largest city in Ghana, and the family medicine programme is also part of the teaching hospital, Komfo Anokye Teaching Hospital. The programme in Mampong is based in a large district hospital, the Tetteh Quarshie Memorial Hospital. A fourth training category of participants included was 'modular residents' who do their training in accredited 'training complexes'. A training complex is a cluster of health facilities including rural district hospitals with affiliated health centres and a regional hospital located in the regional capital.

\section{Participants}

Family medicine residents (PGY2 and PGY3), senior residents and the most recent residency graduates group (at the time of survey distribution) in September 2018 served as the targeted participants. First year residents were excluded since they had only been in the programme for 1 month at the time of survey distribution.

\section{Data collection instrument}

The survey was developed by faculty members of the Family Medicine Department of the University of Michigan (GT and MDF) in collaboration with chair of the Family Medicine unit in Ghana (AE). One of us (GT) visited eligible training sites in the fall of 2017 and met with faculty members and trainees to determine key constructs for inclusion in the survey. The authors designed the data collection instrument to assess the teaching of family medicine in Ghana from the trainees' views. The primary constructs of measurement included four scales: reasons the trainee joined the programme (five items), trainees' assessments of their education (eight items), the teaching strength of the programme (six items) and research opportunities (seven items). We further addressed modalities of learning used, perspectives on the participants' future career and a general demographics questionnaire. The items used 5-point Likert scale questions addressing their views of importance: $5=$ very important, $4=$ important, $3=$ moderately important, $2=$ little importance and $1=$ unimportant, and agreement: $5=$ strongly agree, $4=$ agree, $3=$ neither, $2=$ disagree and $1=$ strongly disagree. 


\section{Data collection process}

We recruited participants by emailing them a Qualtrics link to the survey which was available only for 60 days. Those who logged into the platform, read an informed consent statement and took the survey were considered enrolled. It was distributed to each subject twice to maximise data collection. Data were collected between October and November 2018.

\section{Data entry and statistical analysis}

Participants directly entered their responses into Qualtrics. Their responses were downloaded from Qualtrics, and the dataset was managed using an excel sheet. The analysis was conducted using SAS (Statistical Analysis System) version 9.3 by a statistician at the University of Michigan. The primary outcome of the analysis was interest in academic career. Five-point Likert scale questions about importance were reported by the distribution providing the response. Five-point Likert scale questions about agreement were dichotomised as agree and neither/disagree responses. The study was reviewed and approved by the institutional review boards at the Univeristy of Michigan and the Ghanaian health institute especially given the fact it is anonymous survey with no to minimal harm to subjects.

\section{RESULTS}

Thirty-five of 77 eligible subjects provided responses (46\% response rate), but five records were eliminated due to incomplete data that resulted in a survey completion rate of $39 \%(30 / 77)$. Among 61 subjects in training during survey distribution (PGY2, PGY3 and senior residents the latter who would be called fellows in US terminology), there were 23 subjects in Accra, 13 in Kumasi, 3 in Mampong and 22 who were modular residents. The remaining 16 subjects comprised the most recent graduating cohort from September 2018 (academic year runs September-August). The mean age of the 30 participants providing information was $37(\mathrm{SD}=5)$ years, about the age expected as many medical school graduates have already gained work experience in primary care before entering residency. As table 1 indicates, there were almost twice as many male respondents as females (64\% vs $33 \%)$. A mean of 5.7 ( $\mathrm{SD}=5.2)$ years had elapsed between internship completion and entering a residency programme.

\section{Views on becoming family medicine faculty}

Regarding interest in becoming a faculty member, as illustrated in table 2 , proportionately more men $(13 / 19)$ than women $(4 / 10)$ were considering work as a faculty member. As a group, a higher proportion $(8 / 11)$ of those who had graduated from medical school within 4 years were favourable to an academic path than those $(7 / 14)$ who graduated from medical school 5 or more years prior. The vast majority of those responding $(59 \%(16 / 27))$ appreciated the importance of research. Only 53\% (16/28) showed an interest in becoming a faculty member. Among the training sites,

\begin{tabular}{|c|c|}
\hline $\mathrm{n}=\mathbf{3 0}$ & No. (\%) \\
\hline \multicolumn{2}{|l|}{ Gender } \\
\hline Female & $10(33)$ \\
\hline Male & $19(64)$ \\
\hline Missing & $1(3)$ \\
\hline \multicolumn{2}{|l|}{ Resident type } \\
\hline Graduated (completed training in 2018) & $10(33)$ \\
\hline Resident & $13(43)$ \\
\hline Senior resident & $5(17)$ \\
\hline Missing & $2(7)$ \\
\hline \multicolumn{2}{|l|}{ Primary residency/fellowship site } \\
\hline Accra & $10(33)$ \\
\hline Kumasi & $7(23)$ \\
\hline Mampong & $6(20)$ \\
\hline Modular resident & $4(13)$ \\
\hline Missing & $3(10)$ \\
\hline
\end{tabular}

proportionately, Kumasi and Mampong respondents were more likely to consider working as faculty though this was not statically significant. Participants who had completed a residency programme were much more likely to be interested in becoming faculty when compared with those still in residency $(p<0.001)$. When senior residents (equivalent to fellows in the US system) who had completed residency programme were lumped together with the recent graduates, the relationship remained statistically significant $(\mathrm{p}=0.002)$.

\section{Motives for entering family medicine residency}

Among motives for entering a family medicine training programme as depicted in table 3 , 'needing more education' was the most important factor $93 \%(n=28)$. This was followed by passion for primary care and then procedural training. Only 23\% $(n=7)$ felt income was a big factor in their decision to join a residency programme. While not depicted in the table, $77 \%(\mathrm{n}=23)$ felt the programme provided a high quality of teaching overall. This held true among the vast majority for the inpatient service $83 \%$ $(n=25)$, but only $57 \%(n=17)$ of the respondents rated the teaching quality in the outpatient settings as 'high'.

\section{Views on potential areas of improvement}

When asked what areas of residency training should be improved in the residency programmes, as demonstrated in table 4, 97\% $(\mathrm{n}=29)$ of participants felt the programme needed more faculty members and that the residencies needed more outpatient supervision $(87 \% \quad(n=26)$. They indicated also more need for lectures $83 \%(\mathrm{n}=25)$ as well as supervision in the inpatient setting $80 \%(\mathrm{n}=24)$. Only a minority felt additional rotations were needed $40 \%(n=12)$. 
Table 2 Interest in academic career of the respondents based on age, year since graduation, training site, research interest and training level

\begin{tabular}{|c|c|c|c|}
\hline $\mathrm{n}=\mathbf{3 0}$ & Total proportion (\%) & $\begin{array}{l}\text { Subcategory } \\
\text { proportion (\%) }\end{array}$ & $\begin{array}{l}\text { Fisher exact test } p \\
\text { value }\left(\chi^{2} p \text { value) }\right.\end{array}$ \\
\hline Gender (one missing) & $17 / 29(59)$ & & $0.23(0.28)$ \\
\hline Female & & $4 / 10(40)$ & \\
\hline Year since completion of internship (five missing) & $15 / 25(60)$ & & $0.41(0.46)$ \\
\hline Research importance & $18 / 30(60)$ & & $0.99(1)$ \\
\hline Important & & $16 / 27(59)$ & \\
\hline Moderately to not important & & $2 / 3(67)$ & \\
\hline Training site (three missing) & $15 / 27(56)$ & & $0.62(0.56)$ \\
\hline Modular & & $2 / 4(50)$ & \\
\hline Interested in academic career (two missing) & $16 / 28(57)$ & & $<0.001(0.001)$ \\
\hline Recent graduates & & $10 / 10(100)$ & \\
\hline Current residents & & $3 / 13(23)$ & \\
\hline Senior residents & & $3 / 5(60)$ & \\
\hline
\end{tabular}

\section{Views about research, faculty and programme resources}

As shown in table 5, the participants identified a lack of resources $(90 \%(\mathrm{n}=27))$, research mentorship $(77 \%$ $(\mathrm{n}=23))$ and their own research knowledge $(73 \%(\mathrm{n}=22))$ as the main barriers for research. Regarding perceptions about faculty as illustrated in table $6,93 \%(\mathrm{n}=28)$ had a positive impression of the professionalism of faculty. Also, 73\% ( $\mathrm{n}=22)$ of respondents felt positively about faculty being knowledgeable, caring about resident education and communicating well. In reference to the most frequently accessed learning sources as presented in table 7 , the participants reported most heavily relying, that is over 15 times per month, on online $(40 \%(n=12))$ and book sources $(37 \%(n=11))$. As shown in table 8 , the respondents indicated that the case studies, small group discussions and books were the main learning modalities provided by the programme. However, $73 \%$ $(n=22)$ of respondents felt the programme is lacking online materials, and $63 \%(\mathrm{n}=19)$ of respondents felt the programme is lacking simulation materials.

\section{DISCUSSION}

This is the first known assessment by trainees of the quality of their family medicine residency in this region. As data collection occurred external to the residency infrastructure, we assert the findings as important for being transparent relative to the views of the participating residents. In previous work on the continent in South Africa, a training physician portfolio was found to have a positive educational impact of family medicine trainees, but the research also revealed a lack of assessment skills and feedback by the faculty. ${ }^{44}$ The ability of faculty to provide feedback to trainees is critical for advancing the trainees' career advancement. We anticipate data from this study could help guide thinking about educational content in

Table 3 Motivations for entering family medicine by respondents

\begin{tabular}{llllllc}
\hline & $\begin{array}{l}\text { Very } \\
\text { important } \\
\text { No. (\%) }\end{array}$ & $\begin{array}{l}\text { Important } \\
\text { No. (\%) }\end{array}$ & $\begin{array}{l}\text { Moderately } \\
\text { important } \\
\text { No. (\%) }\end{array}$ & $\begin{array}{l}\text { Of little } \\
\text { importance } \\
\text { No. (\%) }\end{array}$ & $\begin{array}{l}\text { Unimportant } \\
\text { No. (\%) }\end{array}$ & $\begin{array}{l}\text { Missing } \\
\text { No. (\%) }\end{array}$ \\
\hline I needed more education & $28(93)$ & $1(3)$ & 0 & $1(3)$ & 0 & 0 \\
\hline I have a passion for primary care & $20(67)$ & $7(23)$ & $3(10)$ & 0 & 0 & 0 \\
I needed procedure training & $16(53)$ & $10(33)$ & $3(10)$ & $1(3)$ & 0 & 0 \\
\hline Potential for greater income & $7(23)$ & $15(50)$ & $4(13)$ & $3(10)$ & $1(3)$ & 0 \\
Other & $3(10)$ & 0 & $2(7)$ & 0 & 0 & $25(83)$ \\
\hline
\end{tabular}


Table 4 Opportunities for improving the family medicine programme's teaching

\begin{tabular}{|c|c|c|c|}
\hline $\mathrm{n}=30^{*}$ & $\begin{array}{l}\text { SA/A } \\
\text { No. (\%) }\end{array}$ & $\begin{array}{l}\text { N/D/SD } \\
\text { No. (\%) }\end{array}$ & $\begin{array}{l}\text { Missing } \\
\text { No. (\%) }\end{array}$ \\
\hline More faculty members & $29(97)$ & $1(3)$ & 0 \\
\hline $\begin{array}{l}\text { More supervision while seeing } \\
\text { patients in the outpatient setting }\end{array}$ & $26(87)$ & $3(10)$ & $1(3)$ \\
\hline More lectures & $25(83)$ & $5(17)$ & 0 \\
\hline $\begin{array}{l}\text { More supervision during } \\
\text { inpatient rounds }\end{array}$ & $24(80)$ & $5(17)$ & $1(3)$ \\
\hline Include different rotations & $12(40)$ & $6(20)$ & $12(40)$ \\
\hline Other & $3(10)$ & $2(7)$ & $25(83)$ \\
\hline
\end{tabular}

*Percentages based on the row total.

$\mathrm{A}$, agree; $\mathrm{D}$, disagree; $\mathrm{N}$, neutral; SA, strongly agree; SD, strongly disagree.

Ghana and evaluation opportunities for other training programmes in primary care in other parts of West Africa. Such an assessment can also inform curriculum development. These findings highlight the importance of primary care training as well as needs for Ghana. ${ }^{45-48} \mathrm{In}$ light of these findings, the department has expanded and now there is a fourth residency site.

\section{Addressing the shortage of faculty}

These findings confirm observations by the Ghanaian family medicine leadership and the US physician (GT) who visited Ghana that the main challenge in primary care training is the shortage of faculty. Unexpectedly, the survey revealed that during residency, participants did not feel practically interested in pursuing an academic career. However, after completing residency programme, graduates were much more inclined to do so, a statistically significant finding. A plausible explanation is that those who finish residency could be missing the joy of academia. Also, those still in residency training might feel overwhelmed with learning to be a clinician or may lean towards private practice since the latter is financially more rewarding. It is crucial to retain graduates of the

Table 5 Barriers to research according to the family medicine trainees and recent graduates

\begin{tabular}{|c|c|c|c|}
\hline $\mathrm{n}=30^{*}$ & $\begin{array}{l}\text { SA/A } \\
\text { No. }(\%)\end{array}$ & $\begin{array}{l}\text { N/D/SD } \\
\text { No. (\%) }\end{array}$ & $\begin{array}{l}\text { Missing } \\
\text { n (\%) }\end{array}$ \\
\hline $\begin{array}{l}\text { Lack of resources (including } \\
\text { funds) }\end{array}$ & $27(90)$ & $3(10)$ & 0 \\
\hline Lack of mentors & $23(77)$ & $7(23)$ & 0 \\
\hline $\begin{array}{l}\text { Lack of knowledge of } \\
\text { conducting research }\end{array}$ & $22(73)$ & $8(27)$ & 0 \\
\hline Lack of time & $17(57)$ & $13(43)$ & 0 \\
\hline Lack of motivation & $16(53)$ & $14(47)$ & 0 \\
\hline Lack of opportunities & $16(53)$ & $14(47)$ & 0 \\
\hline Other & $2(7)$ & 0 & $28(93)$ \\
\hline
\end{tabular}

*Percentages based on the row total.

$\mathrm{A}$, agree; $\mathrm{D}$, disagree; $\mathrm{N}$, neutral; $\mathrm{SA}$, strongly agree; SD, strongly disagree.
Table 6 Perceptions of faculty by family medicine trainees and recent graduates

\begin{tabular}{|c|c|c|c|}
\hline $\mathrm{n}=30^{*}$ & $\begin{array}{l}\text { SA/A } \\
\text { No. (\%) }\end{array}$ & $\begin{array}{l}\text { N/D/SD } \\
\text { No. (\%) }\end{array}$ & Missing \\
\hline $\begin{array}{l}\text { Faculty members are } \\
\text { professional }\end{array}$ & $28(93)$ & $2(7)$ & 0 \\
\hline Faculty medical knowledge & $22(73)$ & $8(27)$ & 0 \\
\hline $\begin{array}{l}\text { Faculty care about my } \\
\text { education }\end{array}$ & $22(73)$ & $8(27)$ & 0 \\
\hline $\begin{array}{l}\text { Faculty members' } \\
\text { communication skills }\end{array}$ & $22(73)$ & $8(27)$ & 0 \\
\hline Didactics & $18(60)$ & $12(40)$ & 0 \\
\hline Faculty teaching skills & $17(57)$ & $13(43)$ & 0 \\
\hline Feedback from faculty & $15(50)$ & $15(50)$ & 0 \\
\hline $\begin{array}{l}\text { Supervision by faculty during } \\
\text { patient care }\end{array}$ & $12(40)$ & $16(53)$ & $2(7)$ \\
\hline
\end{tabular}

*Percentages based on the row total.

A, agree; D, disagree; N, neutral; SA, strongly agree; SD, strongly disagree.

programme to create the next generation of family medicine teachers in Ghana. Therefore, we suggest better reimbursement models and faculty development for trainees. These findings also revealed that the trainees are passionate about learning. The need for more education was the most commonly reported motive to join a residency programme, more so than improved financial reimbursement. Despite rating inpatient training as of a high quality, the respondents felt the need for more supervisoin in the outpatient as well as in the inpatient settings. Therefore, it is important to have more faculty as well as faculty development programmes. This would justify applying for grants outside Ghana that could help train residents in an academic track. The research instrument developed for this study could be used by other programmes to assess their performance from trainees' perspective and provide comparison data.

\section{Implications for addressing medical student outmigration}

As chronic illnesses are increasing in prevalence among the Ghanaian population and sub-Saharan Africa, there is even greater urgency to produce high-quality primary care doctors to manage the healthcare needs of the general and ageing population. Family medicine is the best available solution to handle the challenges related to comprehensive care and the rise of chronic illnesses. Developing an attractive education curriculum is greatly needed to attract medical students and to help them formulate their specialty decision and future plans. We hope the use of these data will enhance the strength of the teaching programme by having a clear mission that will, in turn, help attract more medical school graduates to join family medicine training. Developing a robust and manageable curriculum is core to this mission. Research in Ghana has shown that the majority of medical students were appreciative of the work of family medicine but few had a good understanding of the specialty. The lack of understanding 
Table 7 Frequency of training modalities accessed by trainees in the family training programme

\begin{tabular}{|c|c|c|c|c|c|c|c|}
\hline $\mathrm{n}=30^{*}$ & $\begin{array}{l}>15 \text { times } \\
\text { No. }(\%)\end{array}$ & $\begin{array}{l}11-15 \text { times } \\
\text { No. }(\%)\end{array}$ & $\begin{array}{l}\text { 7-10 times } \\
\text { No. (\%) }\end{array}$ & $\begin{array}{l}\text { 4-6 times } \\
\text { No. }(\%)\end{array}$ & $\begin{array}{l}\text { 1-3 times } \\
\text { No. (\%) }\end{array}$ & $\begin{array}{l}\text { None } \\
\text { No. (\%) }\end{array}$ & $\begin{array}{l}\text { Missing } \\
\text { No. (\%) }\end{array}$ \\
\hline Online & $12(40)$ & $1(3)$ & $2(7)$ & $2(7)$ & $6(20)$ & $6(20)$ & $1(3)$ \\
\hline Case based & $5(17)$ & $2(7)$ & $5(17)$ & $7(23)$ & $9(30)$ & $2(7)$ & 0 \\
\hline Small group discussion & $4(13)$ & $1(3)$ & $5(17)$ & $4(13)$ & $10(33)$ & $5(17)$ & $1(3)$ \\
\hline Simulation & 0 & 0 & 0 & $3(10)$ & $13(43)$ & $12(40)$ & $2(7)$ \\
\hline Other & 0 & 0 & 0 & 0 & 0 & $3(10)$ & $27(90)$ \\
\hline
\end{tabular}

${ }^{\star}$ Percentages based on the row total.

of family medicine appears to be a barrier for students to choose it as their preferred specialty. ${ }^{33} 49$ Ghana has one of the largest medical school graduates in West Africa with approximately 500 graduates per year. Therefore, effective collaboration between residency programme directors and medical schools could help positively raise awareness among medical students and attract them to join family medicine training. For example, direct entry after completion of the Ghanaian compulsory internship (which is required for entering residency) could help mitigate the loss of medical students to other countries. The structure and enhancements to the residency curriculum will enhance the ability of medical students to better understand their training opportunities in family medicine and to better formulate their decision to enter one of their training sites. ${ }^{50}$ While published data are lacking, there is a general consensus among the Ghanaian family medicine leadership that primary care physicians trained in formal residency programmes provide superior patient care compared with those who have not completed a formal residency programme. Experience from China, which has been transitioning from a shorter training period to a longer training period, suggests other policy makers have reached the same conclusion about the value in training over a longer period of time. ${ }^{951}$

Table 8 Available training modalities provided by the programme according to the trainees and recent graduates

\begin{tabular}{llcc}
\hline & $\begin{array}{l}\text { Yes } \\
\text { No. (\%) }\end{array}$ & $\begin{array}{l}\text { No } \\
\text { No. (\%) }\end{array}$ & $\begin{array}{l}\text { Missing } \\
\text { No. (\%) }\end{array}$ \\
\hline Case based & $25(83)$ & $4(13)$ & $1(3)$ \\
Small group discussion & $22(73)$ & $8(27)$ & 0 \\
Books (hard copies) & $21(70)$ & $9(30)$ & 0 \\
\hline Modular & $19(63)$ & $11(37)$ & 0 \\
Large group lectures & $20(67)$ & $10(33)$ & 0 \\
Simulation & $10(33)$ & $19(63)$ & $1(3)$ \\
Online & $7(23)$ & $22(73)$ & $1(3)$ \\
Other & $2(7)$ & $1(3)$ & $27(90)$ \\
\hline
\end{tabular}

\section{Study limitations}

The primary limitation of this survey is the relatively low response rate. While caution is needed in generalising these opinions, the voices of the responding residents are real, and we have endeavoured to fairly represent them. Importantly, there were roughly similar proportions of respondents from all three sites operating at the time of the survey. Additionally, there is face validity between these results and observations on the ground and discussions between the US consultant (GT) and Ghanaian senior faculty (AE and others) during the preparatory phase of the study. Arguably, the residents' least satisfied with their training would be the least likely to respond. However, we have good reason to believe the low response rate was due in part to logistical issues. First, the survey was only distributed twice during a 60-day period, which was also during the beginning of the busy new academic year. Some of the eligible subjects may have either missed the email invitation (handled as junk mail by their own email systems) or the survey link expired before they had time to complete their responses. This appears to have been the case for at least five incomplete records that were dropped from analysis. Second, the people of Ghana often experience inconsistent internet connectivity. Third, trainees used their own personal emails that are offered through commercial providers and not supported by a residency programme-associated service. Fourth, the US investigator directly emailed the survey link to trainees/graduates to mitigate concern that their responses could be viewed by the programme leadership and potentially result in retribution, but the unknown source could have been problematic as some residents would not be familiar with him.

\section{CONCLUSION}

Having qualified primary care doctors especially in rural areas is critical for the success of Ghana's health system. This feedback from family physicians-in-training and recent graduates provides a window for understanding educational needs based on the perspective of trainees. 
These findings provide a perspective for both local and regional family medicine teachers for evaluating the residency curriculum. The survey findings emphasise the importance of investing in the programmes' current trainees and graduates in order to recruit them into academic roles. Addressing the shortage of faculty appears to be a major challenge to sustaining the family medicine training programme in Ghana. As trainees indicate a relative paucity of educational resources and too few faculty, more government funding is needed. In addition to more online resources, lectures and faculty supervision, strategies are needed to retain residency graduates to become future teachers equipped with faculty development experience. Making changes to enhance training could help make family medicine more attractive to medical school graduates. Ultimately, increasing student interest in family medicine is needed to expand the family physician workforce and address the primary care physician shortage. Beyond the borders of Ghana, the survey could be used in other settings to acquire programme-specific information.

\section{Twitter Michael D Fetters @mdfetters}

Contributors GT participated in study and survey design, data collection, analysis and manuscript writing. AE participated in study and survey design, and manuscript writing. MDF participated in study and survey design, data analysis and manuscript writing.

Funding MDF participation in this research was made possible through the Mixed Methods Program as supported by the Department of Family Medicine, University of Michigan. All participants provided informed consent for this study.

Competing interests None declared.

Patient consent for publication Not required.

Ethics approval This study was approved by the institutional review board (HUM00144881) and the Ghanaian Health Institute.

Provenance and peer review Not commissioned; externally peer reviewed.

Open access This is an open access article distributed in accordance with the Creative Commons Attribution Non Commercial (CC BY-NC 4.0) license, which permits others to distribute, remix, adapt, build upon this work non-commercially, and license their derivative works on different terms, provided the original work is properly cited, appropriate credit is given, any changes made indicated, and the use is non-commercial. See: http://creativecommons.org/licenses/by-nc/4.0/.

\section{ORCID iDs}

Ghazwan Toma http://orcid.org/0000-0001-6836-7587

Akye Essuman http://orcid.org/0000-0002-0784-1123

Michael D Fetters http://orcid.org/0000-0001-8521-5681

\section{REFERENCES}

1 Bodenheimer T, Knox M, Syer S. Interprofessional Care in Teaching Practices: Lessons From "Bright Spots". Acad Med 2018;93:1445-7.

2 Beaulieu M-D, Samson L, Rocher G, et al. Investigating the barriers to teaching family physicians' and specialists' collaboration in the training environment: a qualitative study. BMC Med Educ 2009;9:31.

3 Moosa S, Downing R, Essuman A, et al. African leaders' views on critical human resource issues for the implementation of family medicine in Africa. Hum Resour Health 2014:12:2.

4 Global Burden of Disease Cancer Collaboration, Fitzmaurice C, Akinyemiju TF, et al. Global, regional, and National cancer incidence, mortality, years of life lost, years lived with disability, and disabilityadjusted life-years for 29 cancer groups, 1990 to 2016: a systematic analysis for the global burden of disease study. JAMA Oncol 2018;4:1553-68.

5 Gossa W, Wondimagegn D, Mekonnen D, et al. Key informants' perspectives on development of family medicine training programs in Ethiopia. Adv Med Educ Pract 2016;7:261-9.
6 Flinkenflögel M, Essuman A, Chege P, et al. Family medicine training in sub-Saharan Africa: South-South cooperation in the Primafamed project as strategy for development. Fam Pract 2014;31:427-36.

7 Gossa W, Jones C, Raiculescu S, et al. Family medicine residents' attitudes about training in Ethiopia and the United States. Fam Med 2019;51:424-9.

8 Fetters MD, Kitamura K, Mise J, et al. Japanese and United States family medicine resident physicians' attitudes about training. General Medicine 2002;3:9-16.

9 Lian S, Xia Y, Zhang J, et al. Comparison of general practice residents' attitudes and perceptions about training in two programmes in China: a mixed methods survey. Fam Med Community Health 2019;7:e000238.

10 Hoekzema GS, Maxwell L, Gravel JW, et al. Quality assessment and improvement of post graduate family medicine training in the USA. Educ Prim Care 2016;27:1-5.

11 Frost L, Liddie Navarro A, Lynch M, et al. Care of the elderly: survey of teaching in an aging sub-Saharan Africa. Gerontol Geriatr Educ 2015;36:14-29.

12 Baatiema L, Otim M, Mnatzaganian G, et al. Towards best practice in acute stroke care in Ghana: a survey of hospital services. BMC Health Serv Res 2017;17:108.

13 Tagoe HA. Household burden of chronic diseases in Ghana. Ghana Med J 2012;46:54-8.

14 de-Graft Aikins A, Addo J, Ofei F, et al. Ghana's burden of chronic non-communicable diseases: future directions in research, practice and policy. Ghana Med J 2012;46:1-3.

15 Amalba A, Abantanga FA, Scherpbier AJJA, et al. Working among the rural communities in Ghana - why doctors choose to engage in rural practice. BMC Med Educ 2018;18:133.

16 Mash R. The contribution of family medicine to African health systems. Afr J Prim Health Care Fam Med 2016;8:e1-2.

17 van Nieuwenhuizen B, Zafarmand MH, Beune E, et al. Ideal cardiovascular health among Ghanaian populations in three European countries and rural and urban Ghana: the RODAM study. Intern Emerg Med 2018;13:845-56.

18 Ofori-Asenso R, Garcia D. Cardiovascular diseases in Ghana within the context of globalization. Cardiovasc Diagn Ther 2016;6:67-77.

19 Mobula LM, Sarfo S, Arthur L, et al. A multi-center prospective cohort study to evaluate the effect of differential pricing and health systems strengthening on access to medicines and management of hypertension and diabetes in Ghana: a study protocol. Gates Open Res 2018;2:6.

20 Lassey AT, Lassey PD, Boamah M. Career destinations of University of Ghana medical school graduates of various year groups. Ghana Med J 2013;47:87-91.

21 Duvivier RJ, Burch VC, Boulet JR. A comparison of physician emigration from Africa to the United States of America between 2005 and 2015. Hum Resour Health 2017;15:41.

22 Rodnick JE. Africa: some thoughts on the medical brain drain. Fam Med 2006;38:62-3.

23 Hagopian A, Ofosu A, Fatusi A, et al. The flight of physicians from West Africa: views of African physicians and implications for policy. Soc Sci Med 2005;61:1750-60.

24 Mash R, Downing R, Moosa S, et al. Exploring the key principles of family medicine in sub-Saharan Africa: international Delphi consensus process. S Afr Fam Pract 2008;50:60-5.

25 Drislane FW, Akpalu A, Wegdam HHJ. Establishment of a general medicine residency training program in rural West Africa. Yale $\mathrm{J} \mathrm{Biol}$ Med 2014;87:327-39.

26 Drislane FW, Akpalu A, Wegdam HHJ. The medical system in Ghana. Yale J Biol Med 2014;87:321-6.

27 Essuman A, Agyemang FA, Mate-Kole CC. Long-term care for older adults in Africa: Whither now? J Am Med Dir Assoc 2018;19:728-30.

28 Arya N, Gibson C, Ponka D, et al. Family medicine around the world: overview by region: the Besrour papers: a series on the state of family medicine in the world. Can Fam Physician 2017;63:436-41.

29 Jenkins LS, Von Pressentin K. Family medicine training in Africa: views of clinical trainers and trainees. Afr J Prim Health Care Fam Med 2018;10:e1-4.

30 Ahun MN, Aboud FE, Aryeetey R, et al. Child development in rural Ghana: associations between cognitive/language milestones and indicators of nutrition and stimulation of children under two years of age. Can J Public Health 2017;108:e578-85.

31 McGlynn N, Wilk P, Luginaah I, et al. Increased use of recommended maternal health care as a determinant of immunization and appropriate care for fever and diarrhoea in Ghana: an analysis pooling three demographic and health surveys. Health Policy Plan 2015;30:895-905. 
32 Lamptey P, Laar A, Adler AJ, et al. Evaluation of a community-based hypertension improvement program (ComHIP) in Ghana: data from a baseline survey. BMC Public Health 2017;17:368.

33 Essuman $\mathrm{A}$, Lawson $\mathrm{H}$, Nortey $\mathrm{D}$, et al. Five years of family medicine undergraduate education in Ghana: a wake-up call! Ghana Med 2017;51:50-5.

34 Meyer AC, Opoku C, Gold KJ. "They say I should not think about It:": A qualitative study exploring the experience of infant loss for bereaved mothers in Kumasi, Ghana. Omega 2018;77:267-79.

35 Opoku CA, Browne ENL, Spangenberg K, et al. Perception and risk factors for cervical cancer among women in northern Ghana. Ghana Med J 2016;50:84-9.

36 Petrites AD, Mullan P, Spangenberg K, et al. You have no choice but to go on: how physicians and midwives in Ghana cope with high rates of perinatal death. Matern Child Health J 2016;20:1448-55

37 Spangenberg K, Wobil P, Betts CL, et al. Intimate partner violence among mothers of sick newborns in Ghana. Health Care Women Int 2016;37:583-94.

38 Gold KJ, Jayasuriya TG, Silver JM, et al. How well do mothers in Ghana understand why their newborn is hospitalized? Paediatr Int Child Health 2013;33:181-6.

39 Gold KJ, Spangenberg K, Wobil P, et al. Depression and risk factors for depression among mothers of sick infants in Kumasi, Ghana. Int $J$ Gynaecol Obstet 2013;120:228-31.

40 Essuman A, Gold KJ, Vitale C, et al. Establishing the first geriatric medicine fellowship program in Ghana. J Am Geriatr Soc 2019;67:1718-23.

41 Johnson B, Cayley WE, Nguyen B-M, et al. Faculty development in family medicine education: what is needed? Pan Afr Med $\mathrm{J}$ 2017;26:141.
42 Larson PR, Chege P, Dahlman B, et al. Future of family medicine faculty development in sub-Saharan Africa. Fam Med 2017;49:203-10.

43 Larson PR, Chege P, Dahlman B, et al. Current status of family medicine faculty development in sub-Saharan Africa. Fam Med 2017:49:193-202.

44 Jenkins L, Mash B, Derese A. The national portfolio of learning for postgraduate family medicine training in South Africa: experiences of registrars and supervisors in clinical practice. BMC Med EduC 2013:13:149

45 Ssenyonga R, Seremba E. Family medicine's role in health care systems in sub-Saharan Africa: Uganda as an example. Fam Med 2007;39:623-6.

46 De Maeseneer J, Flinkenflögel M. Primary health care in Africa: do family physicians fit in? Br J Gen Pract 2010;60:286-92.

47 Franey C, Evensen A, Bethune C, et al. Emergence of family medicine in Ethiopia [corrected]: an international collaborative education model. Educ Prim Care 2016;27:241-3.

48 World Health Organization. Country cooperation strategy: Ghana, 2017. Available: https://apps.who.int/gho/data/node.cco

49 Essuman A, Anthony-Krueger C, Ndanu TA. Perceptions of medical students about family medicine in Ghana. Ghana Med $J$ 2013;47:178-84.

50 Berkson D, Kozakowski S. Needs assessment of family medicine residency programs and predoctoral directors. Fam Med 2012;44:189-93.

51 Lian S, Chen Q, Yao M, et al. Training pathways to working as a general practitioner in China. Fam Med 2019;51:262-70. 